\title{
The 50 most cited publications in endoscopic third ventriculostomy: a bibliometric analysis
}

\author{
Nirmeen Zagzoog, MSc, MD, ${ }^{1}$ Ahmed Attar, MBBS, ABPN, FRCPC, ${ }^{2}$ and \\ Kesh Reddy, MBBS, FRCSC, DABNS ${ }^{1}$

\begin{abstract}
'Department of Surgery, Division of Neurosurgery; and 2Department of Medicine, Division of Neurology, Hamilton General Hospital, McMaster University, Hamilton, Ontario, Canada
\end{abstract}

\begin{abstract}
OBJECTIVE Although endoscopic third ventriculostomy (ETV) for the treatment of hydrocephalus was introduced in 1923 , the method was relegated to the sidelines in favor of extracranial techniques. Since the 1990s to the beginning of the current century, however, ETV has undergone a remarkable resurgence to become the first-line treatment for obstructive hydrocephalus, and for some groups, the procedure has been applied for communicating hydrocephalus as well. In the present study, the authors identified the top 50 cited ETV works. These articles represent works of significance that document current practices and provide guidance for future inquiry.
\end{abstract}

METHODS The top 50 cited articles pertaining to ETV were identified using bibliometric data obtained with the Harzing's Publish or Perish software search engine. These high-impact works were evaluated for publication properties including year, country of authorship, category, and journal.

RESULTS The top 50 works were cited an average of 141.02 times with a mean of 9.45 citations per year. Articles published in 2005 were the most numerous in the top 50 group. These top articles were most frequently published in the Journal of Neurosurgery: Pediatrics. Most of the articles were clinical studies reporting on patients in the pediatric age group. The country of most authorship was the US, although many other countries were among the top 50 works.

CONCLUSIONS The present report discusses the bibliometric analysis of the top 50 ETV articles. This list may be useful to those interested in the progress and current status of this procedure.

https://thejns.org/doi/abs/10.3171/2018.2.PEDS17354

KEYWORDS endoscopic third ventriculostomy; noncommunicating hydrocephalus; communicating hydrocephalus; neuroendoscopy

$\mathrm{E}$ NDOSCOPIC third ventriculostomy (ETV) was first proposed in $1923 .{ }^{41}$ By the 1950 s, ETV was shelved when the valved shunt gained prominence for the treatment of hydrocephalus. ${ }^{3}$ As the century mark for ETV approaches, the procedure has emerged as the firstline treatment for obstructive hydrocephalus and has been useful in other secondary forms. Its comeback is owed to a greater scientific understanding of hydrocephalic conditions, radiological advances, technical refinement of the neuroendoscope, and the persistence of the neurosurgical community in overcoming the challenges of hydrocepha- lus. The literature reports on the advances and incorporation of ETV into the neurosurgical armamentarium.

To evaluate the effect a particular report exerts on a specific subject, bibliometric analysis totals the number of citations the publication has achieved. Articles with over 400 lifetime citations are termed "citation classics." Areas of wide study such as aneurysmal subarachnoid hemorrhage are reported to have over 70 citation classics. ${ }^{1}$ In the present study, we identified the top 50 cited ETV works. In this analysis, we acknowledge that the relatively restricted and recent clinical applications of ETV may shape the ci-

ABBREVIATIONS ETV = endoscopic third ventriculostomy.

ACCOMPANYING EDITORIAL See pp 142-144. DOI: 10.3171/2018.6.PEDS18118.

SUBMITTED July 11, 2017. ACCEPTED February 21, 2018.

INCLUDE WHEN CITING Published online October 19, 2018; DOI: 10.3171/2018.2.PEDS17354. 


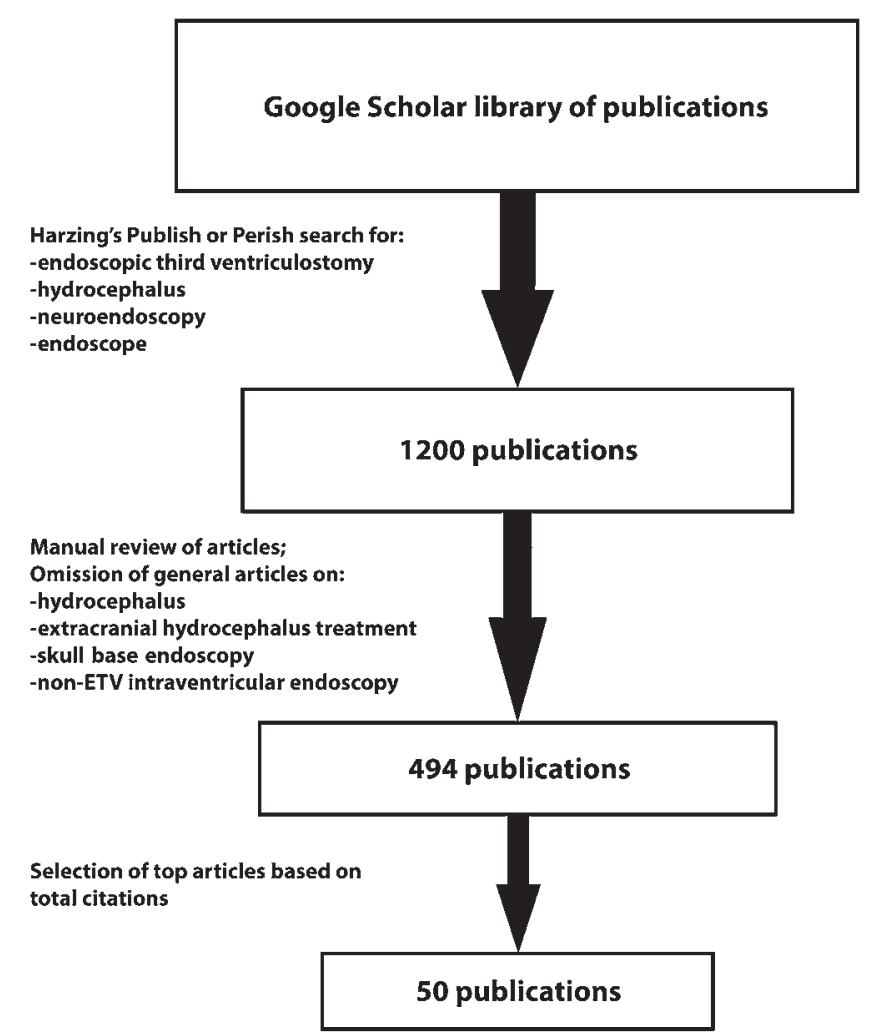

FIG. 1. Schematic of the search and selection process used to identify the top 50 cited articles on ETV.

tation statistics when comparing ETV to other procedures. However, the top listed articles represent works of significance that document current practices and provide guidance for future inquiry.

\section{Methods}

The Harzing's Publish or Perish search engine was utilized to identify the most highly cited ETV publications in a manner similar that done in prior evaluations ${ }^{1,11}$ of other topics. It is a publically available software program that enables the indexing of citations from Google Scholar. The search for journal articles did not restrict the publication date and involved the following search terms: "endoscopic third ventriculostomy," "hydrocephalus," "neuroendoscopy," and "endoscope." Peer-reviewed articles that pertained to ETV and secondary conditions such as tumor, congenital anomalies, or infection were identified. The top 50 cited articles in English-language academic journals were reviewed. The literature about general issues of hydrocephalus or diverse endoscopy techniques that mentioned ETV but concentrated on broader topics were excluded. Such topics included skull base endoscopy, other intraventricular forms of endoscopy, and extracranial hydrocephalus treatments. Book chapters, case reports, patents, and meeting abstracts were also omitted.

To compare search methodologies and to verify our top results, a search was run on the commonly used licensed academic search engine Web of Science using the same keywords and sorting by number of citations. The number of articles returned and the order of the top 50 articles were compared between the two bibliometric analyses.

\section{Data Analysis}

The top 50 cited ETV articles were examined for the following parameters: number of citations, citations per year, year of publication, journal of publication, country of authorship, and category. Authorship with several countries of origin was listed as multinational. The top 20 articles with the highest citations per year were also queried. This search identified works with high yearly citation numbers that may have failed to be in the top 50 because they have not yet earned enough overall citations. Thus, queries of citations per year recognize additional publications but may also exclude others that were listed among the top 50 lifetime citations record.

The articles were categorized into groups: 1) clinical studies, 2) reviews, 3) radiology, and 4) technique. 1) Clinical studies of ETV included single-center or multicenter studies and reports on ETV treatment of communicating and noncommunicating hydrocephalus, outcome analysis, and ETV in combination with congenital anomalies, tumor surgery, choroid plexus coagulation, infection, hemorrhage, and shunt malfunction. These articles were further divided by patient age into pediatric, adult, and mixed pediatric and adult cohorts. 2) Reviews analyzed the status of ETV in the treatment of hydrocephalus. 3) Radiological articles reported on the use of radiology in evaluating CSF flow patterns and outcomes after ETV. 4) Technical articles that discussed procedural aspects of ETV and neuroendoscopy were included in the technique category.

\section{Results}

The steps for selection of the top 50 articles on ETV are outlined in Fig. 1. Over 1200 articles were returned in the literature search. Of these, 494 papers fit the inclusion criteria after manual review. The dates of these articles ranged from 1966 to 2016 . Total citations numbered 17,498 with 343.10 cites per year and 35.42 cites per paper. There were also 171.98 papers per author and 3.65 authors per paper. The 50 articles with the greatest number of citations are listed in Table 1 and yielded 7051 total citations with a mean of 141.02 citations. The article with the greatest number of citations, at $495,{ }^{30}$ was the sole publication in the series to attain the level of citation classic. This article also generated the greatest number of citations per year at 27.5. The top 50 articles had a mean of 9.45 citations per year.

Harzing's Publish or Perish was more effective at filtering search results for relevancy than the commonly used licensed database search engine Web of Science. A search on Web of Science using the same keywords that had been used in Harzing's yielded a total of 33,475 publications. When all of the keywords were used in a search together ("and") instead of individually ("or"), the results were narrowed to only 44 articles, indicating that Harzing's Publish or Perish may also be better suited for identifying a larger portion of the pertinent publications for a topic. Of these 44 articles, only one was in common with our top 50 list: "Endoscopic third ventriculostomy for hydro- 
cephalus" by Gangemi et al. from the journal Minimally Invasive Neurosurgery, ${ }^{22}$ which was the first of the Web of Science results and in 16th place on our list. Most other results returned were general articles on endoscopic neurosurgical techniques.

When the search parameters were changed to prioritize the number of citations per year, three articles ${ }^{26,39,49}$ that had not been included in the overall top 50 entered the list of top 20 articles with the highest number of citations per year. These recently published articles have dates of 2014, 2014, and 2016, respectively. In 2016, Grand et al. published the article "Endoscopic third ventriculostomy in 250 adults with hydrocephalus" in the journal Neurosurgery. ${ }^{26}$ This study is a large, extensively reported clinical series and signifies the application of ETV in adults.

In contrast, 7 articles in the top 50 total citation list did not make the top 20 citations per year query. These articles had publication dates that were more remote, starting in 1978 through 1999. Thus, the search for articles with the highest total citation numbers tended to favor works published earlier. In contrast, the query for articles with the largest number of citations per year introduced more recent articles. This indicates that these publications may be gaining in importance as references but have not yet accrued enough total citations to make the top 50 .

Table 2 depicts the year of publication of the top 50 articles. Publication years in the top 50 articles ranged from 1978 to 2011, with the numbers increasing to the peak year of 2005 (10 articles). It is notable that the earliest top 50 article was published in $1978,{ }^{52}$ with the next earliest in $1990,{ }^{34}$ a gap of 12 years. This finding is consistent with the clinical quiescence of ETV during the period in which extracranial CSF diversion was the prevalent mode of treatment. The significant contribution of large multinational studies in 2005 represents a threshold when the importance of ETV in the treatment of obstructive hydrocephalus was acknowledged in the literature.

Table 3 shows the categories of the top 50 articles. The most favored category consisted of 31 clinical articles, followed by 11 review articles, 5 radiological reports, and 1 paper on technique. Thus, the majority of articles making the top 50 list reported on clinical issues related to ETV, such as risk factors, outcomes including complications, and ETV in combination with congenital anomalies and other conditions, such as infection, tumor, and shunt failure.

The 31 clinical articles were further broken down by patient age, as shown in Table 4. Most clinical articles (67.7\%) reported on patients in the pediatric age group, whereas $9.7 \%$ of articles reported on adults and $22.6 \%$ reported on a mixed combination of pediatric and adult subjects. In the mixed cohorts, patient ages spanned a wide range, from infant to more than 80 years old, with median ages in the 30 s.

Table 5 depicts the authors' countries of publication origin. Authors from a single country wrote each of 16 articles, while the other 34 publications were derived from multiple countries (listed as multinational). The breadth of countries investigating and reporting on ETV is noteworthy. Authors contributing works from a single country originated from Australia, Brazil, Canada, China, France,
TABLE 1. List of the top 50 cited articles on ETV

\begin{tabular}{|c|c|c|c|}
\hline Authors \& Year & Rank & Cites & Cites $/ Y r$ \\
\hline Hopf et al., 1999 & 1 & 495 & 27.50 \\
\hline Jones et al., 1990 & 2 & 358 & 13.23 \\
\hline Cinalli et al., 1999 & 3 & 312 & 17.33 \\
\hline Schroeder et al., 2002 & 4 & 307 & 20.47 \\
\hline Fukuhara et al., 2000 & 5 & 229 & 13.47 \\
\hline Brockmeyer et al., 1998 & 6 & 221 & 11.63 \\
\hline Teo \& Jones, 1996 & 7 & 204 & 9.71 \\
\hline Jones et al., 1994 & 8 & 204 & 8.87 \\
\hline Hellwig et al., 2005 & 9 & 199 & 16.58 \\
\hline Buxton et al., 1998 & 10 & 189 & 9.95 \\
\hline Cinalli et al., 1998 & 11 & 187 & 9.84 \\
\hline Siomin et al., 2002 & 12 & 180 & 12.00 \\
\hline Warf, $2005^{55}$ & 13 & 174 & 14.50 \\
\hline Warf, $2005^{54}$ & 14 & 161 & 13.42 \\
\hline Feng et al., 2004 & 15 & 158 & 12.15 \\
\hline Gangemi et al., 1999 & 16 & 149 & 8.28 \\
\hline Grant \& McLone, 1997 & 17 & 148 & 7.4 \\
\hline Vries, 1978 & 18 & 141 & 3.62 \\
\hline Gangemi et al., 2004 & 19 & 136 & 10.46 \\
\hline Kadrian et al., 2005 & 20 & 132 & 11.00 \\
\hline Beems \& Grotenhuis, 2002 & 21 & 130 & 8.67 \\
\hline Cohen, 1993 & 22 & 128 & 5.33 \\
\hline Pople et al., 2001 & 23 & 127 & 7.94 \\
\hline Kulkarni et al., 2000 & 24 & 125 & 7.35 \\
\hline Drake, 2007 & 25 & 124 & 12.40 \\
\hline Tisell et al., 2000 & 26 & 124 & 7.29 \\
\hline Goumnerova \& Frim, 1997 & 27 & 124 & 6.20 \\
\hline O'Brien et al., 2005 & 28 & 123 & 10.25 \\
\hline Buxton et al., 2001 & 29 & 119 & 7.44 \\
\hline Baldauf et al., 2007 & 30 & 91 & 9.10 \\
\hline Greitz, 2007 & 31 & 89 & 8.90 \\
\hline Drake et al., 2006 & 32 & 86 & 7.82 \\
\hline Wagner \& Koch, 2005 & 33 & 86 & 7.17 \\
\hline Gorayeb et al., 2004 & 34 & 86 & 6.62 \\
\hline Kunz et al., 1994 & 35 & 85 & 3.70 \\
\hline Bouras \& Sgouros, 2011 & 36 & 83 & 13.83 \\
\hline Bargalló et al., 2005 & 37 & 82 & 6.83 \\
\hline Warf et al., 2010 & 38 & 80 & 11.43 \\
\hline Fritsch et al., 2005 & 39 & 79 & 6.58 \\
\hline Ray et al., 2005 & 40 & 79 & 6.58 \\
\hline Jenkinson et al., 2009 & 41 & 78 & 9.75 \\
\hline Ruggiero et al., 2004 & 42 & 76 & 5.85 \\
\hline Kim et al., 2000 & 43 & 76 & 4.47 \\
\hline Kulkarni et al., 2010 & 44 & 75 & 10.71 \\
\hline Wellons et al., 2002 & 45 & 75 & 5.00 \\
\hline Fukuhara et al., 2001 & 46 & 75 & 4.69 \\
\hline Schwartz et al., 1999 & 47 & 75 & 4.17 \\
\hline Jones et al., 1996 & 48 & 63 & 3.00 \\
\hline Erşahin \& Arslan, 2008 & 49 & 62 & 6.89 \\
\hline Amini \& Schmidt, 2005 & 50 & 62 & 5.17 \\
\hline
\end{tabular}


TABLE 2. Year of publication of the top 50 cited articles on ETV

\begin{tabular}{cc}
\hline Year & No. of Articles \\
\hline 1978 & 1 \\
\hline 1990 & 1 \\
\hline 1993 & 1 \\
\hline 1994 & 2 \\
\hline 1996 & 2 \\
\hline 1997 & 2 \\
\hline 1998 & 3 \\
\hline 1999 & 4 \\
\hline 2000 & 4 \\
\hline 2001 & 3 \\
\hline 2002 & 4 \\
\hline 2004 & 4 \\
\hline 2005 & 10 \\
\hline 2007 & 1 \\
\hline 2008 & 3 \\
\hline 2009 & 1 \\
\hline 2010 & 1 \\
\hline 2011 & 2 \\
\hline
\end{tabular}

Germany, Greece, Italy, Korea, the Netherlands, Spain, Sweden, Turkey, Uganda, United Kingdom, and the US. Other countries were also named in the multinational group. Authors from the US had the most numerous papers at 10 , with Germany and the multinational authorships tied for second at 7 articles each. Examining the countries that published the top articles highlights the unique collaborative approach to studying ETV. These reports included multicountry clinical studies, which afforded increased patient numbers beyond what a solitary medical center can supply. The two extensive clinical reports from Uganda $^{54,55}$ were published in 2005 , the year marking the highest number of cited works. These notable publications helped to clarify and then solidify clinical practices for the treatment of hydrocephalus in the pediatric patient group.

Forty-nine of the 50 articles were published in neurosurgical journals (Table 6). The sole outlying article was published in the American Journal of Neuroradiology. ${ }^{5}$ The other 4 radiological reports were published in neurosurgical ${ }^{25,37,47}$ or neurological ${ }^{36}$ journals. Over $50 \%$ of the articles appeared in the Journal of Neurosurgery: Pediatrics, Journal of Neurosurgery, or Neurosurgery.

To give an indication of the level of the quality of the research presented, each of the articles written on clinical

TABLE 3. Categories of the top 50 cited articles on ETV

\begin{tabular}{lc}
\hline Category & No. of Articles \\
\hline Clinical & 31 \\
\hline Review & 11 \\
\hline Radiology & 5 \\
\hline Technique & 1 \\
\hline
\end{tabular}

TABLE 4. Cohort age of the top 50 most cited clinical articles on ETV

\begin{tabular}{lcccc}
\hline \multirow{2}{*}{ Variable } & \multicolumn{4}{c}{ Cohort } \\
\cline { 2 - 5 } & Pediatric & Mixed & Adult & Total \\
\hline No. of articles & 21 & 7 & 3 & 31 \\
\hline$\%$ of total clinical articles & $67.7 \%$ & $22.6 \%$ & $9.7 \%$ & $100 \%$ \\
\hline
\end{tabular}

trials or retrospective analyses of clinical data (40 papers in total) was evaluated for the size of the patient cohort and the type of clinical outcomes investigated. These outcomes were divided into three categories: success rates and morbidities associated with ETV procedures, risk factors and indicators or contraindicators for surgical candidates, and comparison of ETV to other surgical techniques. Table 7 summarizes the number of articles per patient cohort as well as the number of articles addressing each of the clinical outcomes. As hydrocephalus requiring surgical intervention is not especially common at any given institution, cohorts were generally on the smaller side, with nearly half of the articles (19 [47.5\%]) having fewer than 50 patients, 16 articles (40\%) having between 50 and 249 patients, and only 5 articles (12.5\%) having 250 or more patients. Most of the articles focused on assessing the success rates and complications of ETV procedures within a particular institution, population, or demographic, which were largely compared to established success rates and morbidities associated with shunt placement. While all of the papers included this level of evaluation, 15 (37.5\%) included an additional analysis of the patient characteristics or health status that affected, positively or negatively, the likelihood of surgical success or developing a complica-

TABLE 5. Authors' countries of publication origin of the top 50 most cited articles on ETV

\begin{tabular}{lc}
\hline Country & No. of Articles \\
\hline US & 10 \\
\hline Germany & 7 \\
\hline Multinational & 7 \\
\hline Australia & 4 \\
\hline UK & 4 \\
\hline Italy & 3 \\
\hline Canada & 2 \\
\hline France & 2 \\
\hline Sweden & 2 \\
\hline Uganda & 2 \\
\hline Brazil & 1 \\
\hline China & 1 \\
\hline Greece & 1 \\
\hline Korea & 1 \\
\hline Netherlands & 1 \\
\hline Spain & 1 \\
\hline Turkey & 1 \\
\hline
\end{tabular}

UK = United Kingdom. 
TABLE 6. Journals of the top 50 most published articles on ETV

\begin{tabular}{lc}
\hline \multicolumn{1}{c}{ Journal } & No. of Articles \\
\hline J Neurosurg Peds & 10 \\
\hline Neurosurgery & 9 \\
\hline J Neurosurg & 7 \\
\hline Childs Nerv Syst & 6 \\
\hline Pediatr Neurosurg & 5 \\
\hline Minim Invasive Neurosurg & 3 \\
\hline Surg Neurol & 3 \\
\hline Neurosurg Focus & 2 \\
\hline AJNR Am J Neuroradiol & 1 \\
\hline Br J Neurosurg & 1 \\
\hline Eur J Pediatr Surg & 1 \\
\hline Neurosurg Rev & 1 \\
\hline World Neurosurg & 1 \\
\hline
\end{tabular}

tion. Only 6 of the articles (15\%) presented a comparison of techniques, such as endoscopy versus other forms of guidance for ventriculostomy, which arguably contributed the greatest value in new knowledge about ETV procedures in the field of neurosurgery.

\section{Discussion}

Bibliometrics affords an understanding of the status and trends of publications over time by identifying the highly cited articles within a field of study. These metrics pinpoint significant articles that by total citation numbers may be important in understanding the present state of a particular practice. The trends within a bibliometric analysis can also aid in understanding the historical evolution of a subject as article rankings can shift over time as new articles are added and others drop off the top 50.

The literature for ETV was analyzed using bibliometrics. Although ETV is a clinical intervention that was proposed nearly a century ago, it has had a major resurgence in application as various technological and clinical advances have matured. This is reflected in the dearth of top 50 articles in the 12 years following the earliest top 50 article in $1978 .^{7}$ Thereafter, the output of publications appearing in the top 50 cited articles increased starting in the late 1990s to early 2000 and peaked at 2005 .

Despite the growing importance of ETV in the treatment of hydrocephalus, the "modern" era of ETV is still young. Among the top articles, there is only one citation classic, ${ }^{30}$ as compared to over 70 reports in the aneurysmal subarachnoid hemorrhage literature. Endoscopic third ventriculostomy is a relatively narrow field thus far, and the procedure is predominantly utilized in the pediatric age group. Over half of the top 50 articles are clinical studies. Within the clinical category, the majority $(67.7 \%)$ of studies were conducted in pediatric patients. As the indications for ETV expand to include younger infants and more adults, a bimodal age curve in the literature may likely develop.

Six of 10 articles published before 2005 reported on studies involving mixed age groups. Later articles focused solely on the pediatric age group and included infants younger than 1 year who had undergone ETV in combination with choroid plexus cauterization. The question of how ETV applies to both the very young and adults continues to be the topic of intense investigation. This trend is evidenced by three articles, two from $2014^{39,49}$ and one from $2016,{ }^{26}$ which earned high cites per year but failed to make the top 50 citation group. The indications for ETV in communicating forms of hydrocephalus and those with shunt history may be more relevant in the adult age group. These matters may lead to publications that will change the ETV bibliometrics of this report.

Only five top 50 articles were concentrated on radiological analysis. $5,25,36,37,47$ Of these, only one was published in a radiological journal, the American Journal of Neuroradiology. ${ }^{5}$ The authors of this article analyzed post-ETV patency with MRI. Radiological studies will likely continue to become even more important in the overall management of ETV, especially as the routine availability of MRI improves in the developing world. As more emphasis is placed on characterizing long-term outcomes, other parameters of clinical success, such as outcome scores and neurocognitive evaluations, may combine with radiological assessments to determine the effectiveness of ETV over time. The neurocognitive assessments lacking in the present top 50 group may be more necessary as the young patient population with ETV ages.

The geography of the top 50 publications is illuminating and a testament to international neurosurgical collaboration and perseverance. The majority of articles were published in US-based publications: Journal of Neurosurgery: Pediatrics, Journal of Neurosurgery, and Neurosurgery. Although authors from the US wrote the most top 50 cited articles, more than 15 other countries also contributed works to the top 50 list. Seven papers were authored by multicenter, multinational groups, which serve as models for international collaboration when solitary institutional numbers may be too low to effect a change in practice recommendations. The 2005 articles by Warf, on a series in Uganda, ${ }^{54,55}$ are important to note. This work, based on a large clinical experience, represents a contribution to both the improvement of public health in Uganda and the overall understanding of ETV in the worldwide

TABLE 7. Summary of the number of articles including cohort size and clinical parameters*

\begin{tabular}{lcccccccc}
\hline \multirow{2}{*}{ Variable } & \multicolumn{3}{c}{ Cohort Size } & & \multicolumn{3}{c}{ Clinical Parameters Evaluated } \\
\cline { 2 - 4 } & $1-49$ & $50-249$ & $250+$ & & Success Rates \& Morbidities & Risk Factors \& Indicators & Comparative Techniques \\
\hline No. of articles & 19 & 16 & 5 & & 40 & 15 & 6 \\
\hline$\%$ of total clinical articles & $47.5 \%$ & $40 \%$ & $12.5 \%$ & & $100 \%$ & $37.5 \%$ & $15 \%$ \\
\hline
\end{tabular}

\footnotetext{
${ }^{*}$ Among 40 papers total.
} 
pediatric population. These Ugandan studies prove that it is possible to employ advanced neurosurgical technology in a developing country, particularly when the existing treatment options are suboptimal, i.e., shunting, within the limitations of available resources.

Medical bibliometric analysis is a traditional approach to measuring citation metrics. Thus, bibliometric reports, including the current one, have intrinsic limitations. These methods provide a quantitative means to estimate a particular work's impact on the literature and do not critique the quality of the work per se. As the types of studies and articles varied widely with vastly different methodologies, there is no standardized empirical method for evaluating the scientific rigor of a study's design. However, like other experiments, which select a measurable factor as an indicator for a complex phenomenon, citation analysis can be assumed to reflect the relative contribution of a paper to its field and, by extension, the quality of the research or information it conveys. Further manual evaluation following an algorithmic selection based on citation number is therefore needed to confirm the quality of the selected works. The current study relies on Web-based search platforms such as Google Scholar and software programs to answer queries for articles based on citation numbers. Every attempt was made to verify the results using the software Web-based queries and then, secondarily, by manual review. Our current analysis was restricted to English-language journals and therefore may have missed significant contributions from authors of non-English papers.

Tallying the top articles based on the number of citations may overvalue those that appear on the list and undervalue those that are left out. The lists that have been described in this report are representative of a moment in time. As articles are being published and referenced, rankings will tend to change, particularly with the proliferation of subspecialty journals and online venues for publishing. Internet sites including forums, social media, blogs, reference managers, and multimedia sites are not included in bibliometric evaluations. Altmetrics has been proposed as an additional modality to study a work's online engagements, including mentions, downloads, saves, and views. ${ }^{11}$ Still, bibliometric analyses are helpful in understanding the literature within a topic, for observing trends, and in discussing potential directions. Google Scholar does include some extra-literature works such as slideshow presentations in its citations listings. Concerns that this artificially inflates the citation scores of some publications have been expressed; however, it may bring a more accurate representation of the modern impact of a work by including some nontraditional references. While search results using Google Scholar are skewed by inconsistent keyword searches, this issue is avoided by using analytical software such as Publish or Perish. In the future, similar reports may employ altmetrics as an additional tool to calculate a work's standing in real time.

The story of ETV crosses time and geography and stands as a model for international collaboration. Its history reinforces the idea that new knowledge can lead to steps that reinvigorate a dormant methodology. As the first century of ETV closes, the postmodern era of studies will launch. This era will further clarify the indications for
ETV and, we hope, drill down on the specific disorders for which this procedure is most useful. The patient groups that can benefit from ETV may increase as the pediatric studies separate from those in adults. Radiological indicators may also combine with clinical indicators to establish measures of a successful outcome. Eventually these may be applied against results for the extracranial diversion techniques to consolidate best practice guidelines.

\section{Conclusions}

Using bibliometric methods, we identified the top 50 most cited ETV articles from peer-reviewed journals. Median total citations and citations per year were calculated. These articles were examined for year of publication, category, country of authorship, and journal. This analysis highlights how these parameters are understood against the backdrop of the clinical application of ETV.

\section{References}

1. Alotaibi NM, Nassiri F, Badhiwala JH, Witiw CD, Ibrahim GM, Macdonald RL, et al: The most cited works in aneurysmal subarachnoid hemorrhage: a bibliometric analysis of the 100 most cited articles. World Neurosurg 89:587-592, 592. e1-592.e6, 2016

2. Amini A, Schmidt RH: Endoscopic third ventriculostomy in a series of 36 adult patients. Neurosurg Focus 19(6): E9, 2005

3. Aschoff A, Kremer P, Hashemi B, Kunze S: The scientific history of hydrocephalus and its treatment. Neurosurg Rev 22:67-95, 1999

4. Baldauf J, Oertel J, Gaab MR, Schroeder HW: Endoscopic third ventriculostomy in children younger than 2 years of age. Childs Nerv Syst 23:623-626, 2007

5. Bargalló N, Olondo L, Garcia AI, Capurro S, Caral L, Rumia $\mathrm{J}$ : Functional analysis of third ventriculostomy patency by quantification of CSF stroke volume by using cine phase-contrast MR imaging. AJNR Am J Neuroradiol 26:2514-2521, 2005

6. Beems T, Grotenhuis JA: Is the success rate of endoscopic third ventriculostomy age-dependent? An analysis of the results of endoscopic third ventriculostomy in young children. Childs Nerv Syst 18:605-608, 2002

7. Bouras T, Sgouros S: Complications of endoscopic third ventriculostomy. J Neurosurg Pediatr 7:643-649, 2011

8. Brockmeyer D, Abtin K, Carey L, Walker ML: Endoscopic third ventriculostomy: an outcome analysis. Pediatr Neurosurg 28:236-240, 1998

9. Buxton N, Ho KJ, Macarthur D, Vloeberghs M, Punt J, Robertson I: Neuroendoscopic third ventriculostomy for hydrocephalus in adults: report of a single unit's experience with 63 cases. Surg Neurol 55:74-78, 2001

10. Buxton N, Macarthur D, Mallucci C, Punt J, Vloeberghs M: Neuroendoscopic third ventriculostomy in patients less than 1 year old. Pediatr Neurosurg 29:73-76, 1998

11. Chavda J, Patel A: Measuring research impact: bibliometrics, social media, altmetrics, and the BJGP. Br J Gen Pract 66:e59-e61, 2016

12. Cinalli G, Sainte-Rose C, Chumas P, Zerah M, Brunelle F, Lot G, et al: Failure of third ventriculostomy in the treatment of aqueductal stenosis in children. J Neurosurg 90:448-454, 1999

13. Cinalli G, Salazar C, Mallucci C, Yada JZ, Zerah M, SainteRose C: The role of endoscopic third ventriculostomy in the management of shunt malfunction. Neurosurgery 43:13231329,1998 
14. Cohen AR: Endoscopic ventricular surgery. Pediatr Neurosurg 19:127-134, 1993

15. Drake J, Chumas P, Kestle J, Pierre-Kahn A, Vinchon M, Brown J, et al: Late rapid deterioration after endoscopic third ventriculostomy: additional cases and review of the literature. J Neurosurg 105 (2 Suppl):118-126, 2006

16. Drake M: Endoscopic third ventriculostomy in pediatric patients: the Canadian experience. Neurosurgery 60:881-886, 2007

17. Erşahin Y, Arslan D: Complications of endoscopic third ventriculostomy. Childs Nerv Syst 24:943-948, 2008

18. Feng H, Huang G, Liao X, Fu K, Tan H, Pu H, et al: Endoscopic third ventriculostomy in the management of obstructive hydrocephalus: an outcome analysis. J Neurosurg 100:626-633, 2004

19. Fritsch MJ, Kienke S, Ankermann T, Padoin M, Mehdorn HM: Endoscopic third ventriculostomy in infants. J Neurosurg 103 (1 Suppl):50-53, 2005

20. Fukuhara T, Luciano MG: Clinical features of late-onset idiopathic aqueductal stenosis. Surg Neurol 55:132-137, 2001

21. Fukuhara T, Vorster SJ, Luciano MG: Risk factors for failure of endoscopic third ventriculostomy for obstructive hydrocephalus. Neurosurgery 46:1100-1111, 2000

22. Gangemi M, Donati P, Maiuri F, Longatti P, Godano U, Mascari C: Endoscopic third ventriculostomy for hydrocephalus. Minim Invasive Neurosurg 42:128-132, 1999

23. Gangemi M, Maiuri F, Buonamassa S, Colella G, de Divitiis E: Endoscopic third ventriculostomy in idiopathic normal pressure hydrocephalus. Neurosurgery 55:129-134, 2004

24. Gorayeb RP, Cavalheiro S, Zymberg ST: Endoscopic third ventriculostomy in children younger than 1 year of age. $\mathbf{J}$ Neurosurg 100 (5 Suppl Pediatrics):427-429, 2004

25. Goumnerova LC, Frim DM: Treatment of hydrocephalus with third ventriculocisternostomy: outcome and CSF flow patterns. Pediatr Neurosurg 27:149-152, 1997

26. Grand W, Leonardo J, Chamczuk AJ, Korus AJ: Endoscopic third ventriculostomy in 250 adults with hydrocephalus: patient selection, outcomes, and complications. Neurosurgery 78:109-119, 2016

27. Grant JA, McLone DG: Third ventriculostomy: a review. Surg Neurol 47:210-212, 1997

28. Greitz D: Paradigm shift in hydrocephalus research in legacy of Dandy's pioneering work: rationale for third ventriculostomy in communicating hydrocephalus. Childs Nerv Syst 23:487-489, 2007

29. Hellwig D, Grotenhuis JA, Tirakotai W, Riegel T, Schulte DM, Bauer BL, et al: Endoscopic third ventriculostomy for obstructive hydrocephalus. Neurosurg Rev 28:1-38, 2005

30. Hopf NJ, Grunert P, Fries G, Resch KD, Perneczky A: Endoscopic third ventriculostomy: outcome analysis of 100 consecutive procedures. Neurosurgery 44:795-806, 1999

31. Jenkinson MD, Hayhurst C, Al-Jumaily M, Kandasamy J, Clark S, Mallucci CL: The role of endoscopic third ventriculostomy in adult patients with hydrocephalus. J Neurosurg 110:861-866, 2009

32. Jones RF, Kwok BC, Stening WA, Vonau M: The current status of endoscopic third ventriculostomy in the management of non-communicating hydrocephalus. Minim Invasive Neurosurg 37:28-36, 1994

33. Jones RF, Kwok BC, Stening WA, Vonau M: Third ventriculostomy for hydrocephalus associated with spinal dysraphism: indications and contraindications. Eur J Pediatr Surg 6 (Suppl 1):5-6, 1996

34. Jones RF, Stening WA, Brydon M: Endoscopic third ventriculostomy. Neurosurgery 26:86-92, 1990

35. Kadrian D, van Gelder J, Florida D, Jones R, Vonau M, Teo C, et al: Long-term reliability of endoscopic third ventriculostomy. Neurosurgery 56:1271-1278, 2005

36. Kim SK, Wang KC, Cho BK: Surgical outcome of pediatric hydrocephalus treated by endoscopic III ventriculostomy: prognostic factors and interpretation of postoperative neuroimaging. Childs Nerv Syst 16:161-169, 2000

37. Kulkarni AV, Drake JM, Armstrong DC, Dirks PB: Imaging correlates of successful endoscopic third ventriculostomy. J Neurosurg 92:915-919, 2000

38. Kulkarni AV, Drake JM, Kestle JR, Mallucci CL, Sgouros S, Constantini S: Predicting who will benefit from endoscopic third ventriculostomy compared with shunt insertion in childhood hydrocephalus using the ETV Success Score. J Neurosurg Pediatr 6:310-315, 2010

39. Kulkarni AV, Riva-Cambrin J, Browd SR, Drake JM, Holubkov R, Kestle JR, et al: Endoscopic third ventriculostomy and choroid plexus cauterization in infants with hydrocephalus: a retrospective Hydrocephalus Clinical Research Network study. J Neurosurg Pediatr 14:224-229, 2014

40. Kunz U, Goldmann A, Bader C, Waldbaur H, Oldenkott P: Endoscopic fenestration of the 3rd ventricular floor in aqueductal stenosis. Minim Invasive Neurosurg 37:42-47, 1994

41. Mixter WJ: Ventriculoscopy and puncture of the floor of the third ventricle. Boston Med Surg J 188:277-278, 1923

42. O'Brien DF, Javadpour M, Collins DR, Spennato P, Mallucci CL: Endoscopic third ventriculostomy: an outcome analysis of primary cases and procedures performed after ventriculoperitoneal shunt malfunction. J Neurosurg 103 (5 Suppl):393-400, 2005

43. Pople IK, Athanasiou TC, Sandeman DR, Coakham HB: The role of endoscopic biopsy and third ventriculostomy in the management of pineal region tumours. Br J Neurosurg 15:305-311, 2001

44. Ray P, Jallo GI, Kim RY, Kim BS, Wilson S, Kothbauer K, et al: Endoscopic third ventriculostomy for tumor-related hydrocephalus in a pediatric population. Neurosurg Focus 19(6):E8, 2005

45. Ruggiero C, Cinalli G, Spennato P, Aliberti F, Cianciulli E, Trischitta V, et al: Endoscopic third ventriculostomy in the treatment of hydrocephalus in posterior fossa tumors in children. Childs Nerv Syst 20:828-833, 2004

46. Schroeder HW, Niendorf WR, Gaab MR: Complications of endoscopic third ventriculostomy. J Neurosurg 96:10321040,2002

47. Schwartz TH, Ho B, Prestigiacomo CJ, Bruce JN, Feldstein NA, Goodman RR: Ventricular volume following third ventriculostomy. J Neurosurg 91:20-25, 1999

48. Siomin V, Cinalli G, Grotenhuis A, Golash A, Oi S, Kothbauer K, et al: Endoscopic third ventriculostomy in patients with cerebrospinal fluid infection and/or hemorrhage. J Neurosurg 97:519-524, 2002

49. Stone SS, Warf BC: Combined endoscopic third ventriculostomy and choroid plexus cauterization as primary treatment for infant hydrocephalus: a prospective North American series. J Neurosurg Pediatr 14:439-446, 2014

50. Teo C, Jones R: Management of hydrocephalus by endoscopic third ventriculostomy in patients with myelomeningocele. Pediatr Neurosurg 25:57-63, 1996

51. Tisell M, Almström O, Stephensen H, Tullberg M, Wikkelsö C: How effective is endoscopic third ventriculostomy in treating adult hydrocephalus caused by primary aqueductal stenosis? Neurosurgery 46:104-111, 2000

52. Vries JK: An endoscopic technique for third ventriculostomy. Surg Neurol 9:165-168, 1978

53. Wagner W, Koch D: Mechanisms of failure after endoscopic third ventriculostomy in young infants. J Neurosurg 103 (1 Suppl):43-49, 2005

54. Warf BC: Comparison of endoscopic third ventriculostomy alone and combined with choroid plexus cauterization in infants younger than 1 year of age: a prospective study in 550 African children. J Neurosurg 103 (6 Suppl):475-481, 2005

55. Warf BC: Hydrocephalus in Uganda: the predominance of 
infectious origin and primary management with endoscopic third ventriculostomy. J Neurosurg 102 (1 Suppl): 1-15, 2005

56. Warf BC, Mugamba J, Kulkarni AV: Endoscopic third ventriculostomy in the treatment of childhood hydrocephalus in Uganda: report of a scoring system that predicts success. J Neurosurg Pediatr 5:143-148, 2010

57. Wellons JC III, Tubbs RS, Banks JT, Grabb B, Blount JP,

Oakes WJ, et al: Long-term control of hydrocephalus via endoscopic third ventriculostomy in children with tectal plate gliomas. Neurosurgery 51:63-68, 2002

\section{Author Contributions}

Conception and design: all authors. Acquisition of data: Zagzoog. Analysis and interpretation of data: Zagzoog. Drafting the article: Zagzoog. Critically revising the article: all authors. Reviewed submitted version of manuscript: Zagzoog. Approved the final version of the manuscript on behalf of all authors: Zagzoog.

\section{Correspondence}

Nirmeen Zagzoog: McMaster University, Hamilton General Hospital, Hamilton, ON, Canada.nirmeen.zagzoog@medportal.ca.

\section{Disclosures}

The authors report no conflict of interest concerning the materials or methods used in this study or the findings specified in this paper. 